\title{
Effectiveness Test of Orchid Mycorrhizal Isolate (Ceratorhiza and Trichoderma) Indonesia and Its Role as a Biofertilizer
}

\author{
Mahfut $^{1^{\star}}$, Budi Setiadi Daryono ${ }^{2}$, Ari Indrianto $^{2}$ and Susamto Somowiyarjo ${ }^{3}$ \\ ${ }^{1}$ Faculty of Mathematics and Natural Sciences, University of Lampung, Lampung, 35145, Indonesia. \\ ${ }^{2}$ Faculty of Biology, Gadjah Mada University, Yogyakarta 55281, Indonesia. \\ ${ }^{3}$ Faculty of Agriculture, Gadjah Mada University, Yogyakarta 55281, Indonesia.
}

\begin{abstract}
Authors' contributions
This work was carried out in collaboration among all authors. Author Mahfut designed the study, performed the statistical analysis, wrote the protocol and wrote the first draft of the manuscript. As a

promotor and co-promotor for my PhD program study, authors BSD, Al and SS managed the analyses of the study and managed the literature searches. All authors read and approved the final manuscript.

Article Information

DOI: $10.9734 / A R R B / 2019 / v 33 i 430127$

Editor(s):

(1) Dr. Rishee K. Kalaria, Assistant Professor, Bioinformatics Section, Aspee Shakilam Biotechnology Institute, Navsari Agricultural University, Surat, India.

Reviewers:

(1) Ann A. J. Mofunanya, University of Calabar, Nigeria.

(2) R. Mahalakshmi, India. Complete Peer review History: http://www.sdiarticle4.com/review-history/52125
\end{abstract}

Original Research Article

Received 07 August 2019

Accepted 17 October 2019

Published 28 October 2019

\section{ABSTRACT}

Aim: The existence of Orchid Mycorrhizal Fungi (OMF) has a role to stimulate growth and support the supply of orchid nutrition as a biofertilizer agent. This study aimed to determine the association of mycorrhizal with Phalaenopsis amabilis (L.) Blume which was carried out through the effectiveness test of two Indonesian orchid mycorrhizal isolates i.e. Ceratorhiza and Trichoderma.

Study Design: This study consisted of 4 treatments. Each treatment was repeated 3 times, each repetition of 5 plantlets, so that the total plantlet used was 60 .

Place and Duration of Study: Laboratory of Plant Biotechnology, Department of Biology, Universitas Gadjah Mada, Indonesia, between June 2017 and April 2018.

Methodology: The method of inoculating orchid mycorrhizal by placing a plantlet in a petri dish containing orchid mycorrhizal for 1,2, 3, and 4 days. Then plantlets are grown on sterile moss 
growing media and acclimatized in a greenhouse. Observation of each treatment is carried out every day for the next month. Observation variables include the number of initial and final roots, the number of live and dead roots, and the number of living and dead plants.

Results: The results of the orchid mycorrhizal induction test showed that the Ceratorhiza inoculation treatment showed a fluctuation in the mean increase in the number of final roots, live roots, dead roots, and dead plantlets that were higher than the Trichoderma inoculation treatment. The results also showed that the best inoculation time on Ceratorhiza and Trichoderma was day 3 and 4 . The adaptation process had the effect of increasing the number of dead roots in weeks 1 and 2 . The adaptation process stopped at the beginning of week 4 with the number of new roots appearing a lot.

Conclusion: Orchid mycorrhizal Ceratorhiza shows the value of effectiveness test compared with Trichoderma. The results of this study are expected to be basic information in efforts to cultivate natural orchids in Indonesia.

Keywords: Orchid mycorrhizal; Ceratorhiza; Trichoderma; Phalaenopsis amabilis (L.) blume; Indonesia.

\section{INTRODUCTION}

The presence of endophytic mycorrhizal as Orchid Mycorrhizal Fungi (OMF) in orchid plants is known to play an important role in stimulating orchid seed germination [1], supporting the supply of plantlet nutrition [2,3], helping the formation of more buds and flower buds [2], and control biological agents by inducing resistance to bacterial infection of Erwinia chrysanthemi [4] and inhibiting the replication of ORSV and CymMV [5]. But its presence in different plants can be as a disease-causing agent (pathogen).

Previous studies have identified the isolates of Ceratorhiza and Trichoderma isolated from the roots of the orchid Phalaenopsis amabilis L. (Blume) in Yogyakarta, Indonesia. Identification of the two is distinguished by observing morphological and molecular characters [6]. Molecular analysis was carried out based on the identification of the rDNA-ITS sequence, while morphological analysis was done by observing the surface colour, appearance and colony growth rate, hyphae colour and diameter, shape and size of monilioid cells, and the number of nuclei [7].

Soelistijono et al. [6] reported that induction of Ceratorhiza and Tricoherma mycorrhizal are as a biofertilizer (organic fertilizer). Mycorrhiza works to improve the structure of the soil around plant roots by breaking down organic substances in the soil. The presence of organic substances in the soil is abundant but the shape and size that cannot be absorbed by plants. Besides saving costs, the use of mycorrhizal is very safe for the environment. In the sequel, the mycorrhizal application can accelerate the growth and development of orchid plantlets. Based on this, further research needs to be carried out on the effectiveness of both Indonesian isolate endophytic mycorrhizal and their role as biofertilizer. This research is expected to be important information in the cultivation and development potential of Phalaenopsis amabilis L. (Blume) in Indonesia.

\section{MATERIALS AND METHODS}

\subsection{Source of Orchid Mycorrhizal Isolates}

The isolates used were Ceratorhiza and Trichoderma isolate collected from the root of $P$. amabilis L. (Blume) in Yogyakarta. Pure isolates were bred on Potato Dextrose Agar (PDA) media. Inoculum incubation is carried out in a dark room at room temperature until the age of 7 days.

\subsection{Source of Orchid Plantlet}

The orchid plantlet used was 12 months old $P$. amabilis L. (Blume) cultured from seeds on Murashige and Skoog (MS) media. Plantlets are removed from culture bottles and soaked in a fungicide solution ( $2 \mathrm{~g} / \mathrm{l}$ water) for 20 minutes. Plantlet is then planted on sterile moss media. Orchids are grown properly for 1 month before treatment. Watering is done twice a week using a spray tool.

\subsection{Orchid Mycorrhizal Inoculation}

Orchid mycorrhizal inoculation in this study used the method of Nuangmek et al. [8]. Orchid mycorrhizal are grown in Petri dishes $9 \mathrm{~cm}$ in diameter. Plantlet is placed in a petri dish containing orchid mycorrhizal for $1,2,3$, and 4 
days. Then the plantlets are regrown on sterile moss growing media and acclimatized in a greenhouse. This study consisted of 4 treatments. Each treatment was repeated 3 times, each repetition of 5 plantlets, so that the total plantlet used was 60 .

\subsection{Observation of the Orchid Mycorrhizal Effectiveness Test}

The effectiveness of orchid mycorrhizal on plantlets was carried out in vivo. Observation of each treatment is carried out every day for the next month. Observation variables include the number of initial and final roots, the number of live and dead roots, and the number of living and dead plants.

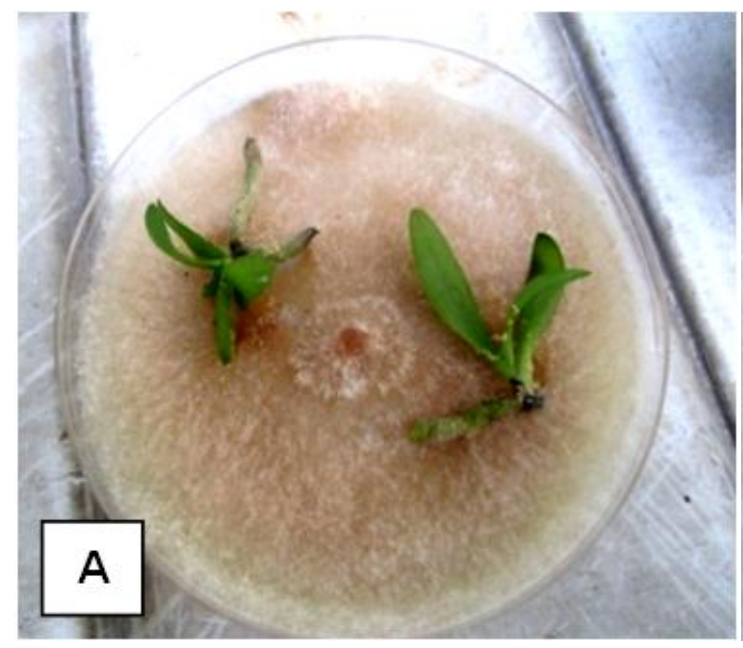

\section{RESULTS AND DISCUSSION}

\subsection{Inoculation of Orchid Mycorrhizal}

The results of orchid mycorrhizal inoculation showed hyphae would envelop the roots of the plantlet. The hyphae were getting thicker with the length of treatment (Fig. 1).

\subsection{Observation of Orchid Mycorrhizal Effectiveness Test}

The effectiveness of orchid mycorrhizal was carried out through observations of growth and survival ability of post-inoculation plantlet shown in Tables 1-4.

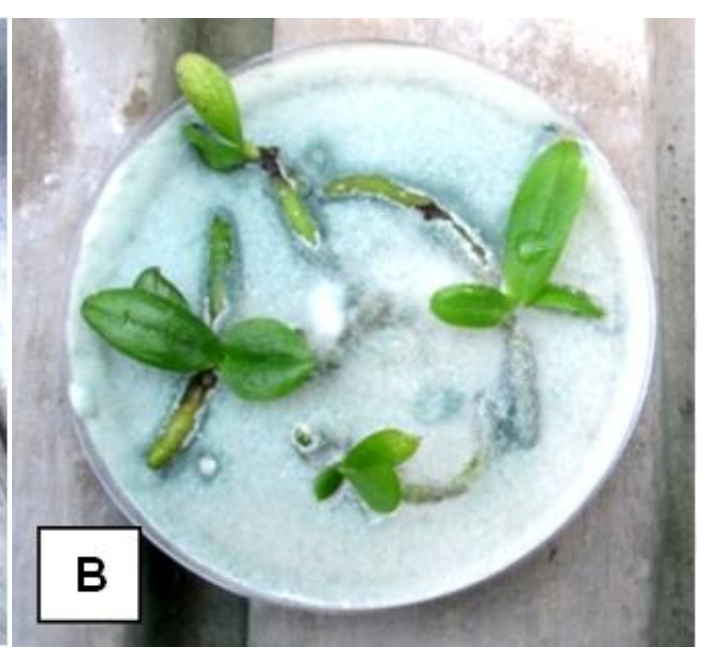

Fig. 1. Orchid mycorrhizal inoculation by placing plantlets on (A) Ceratorhiza and (B) Trichoderma isolates in a petri dish at 4 days treatment

Table 1. Mean effectiveness of orchid mycorrhizal test results at $1^{\text {st }}$ week

\begin{tabular}{|c|c|c|c|c|c|c|c|}
\hline \multirow{2}{*}{$\begin{array}{l}\text { Orchid } \\
\text { mycorrhizal } \\
\text { isolates }\end{array}$} & \multirow{2}{*}{$\begin{array}{l}\text { Duration of } \\
\text { incubation } \\
\text { (Day) }\end{array}$} & \multicolumn{6}{|c|}{ Observation of effectiveness Test ( $1^{\text {st }}$ week) } \\
\hline & & $\begin{array}{l}\sum_{\text {(Initial) }} \text { Root } \\
\text { (I) }\end{array}$ & $\sum_{\text {(End) }}$ Root & $\begin{array}{l}\sum_{\text {(Life) }} \text { Root } \\
\text { (Life }\end{array}$ & $\begin{array}{l}\sum_{\text {(Dead) }} \text { Root } \\
\text { (Ded }\end{array}$ & $\begin{array}{l}\sum_{\text {(Life) }} \text { Plantlet } \\
\end{array}$ & $\sum_{\text {(Dead) }}$ Plantlet \\
\hline Control & - & 7 & 7 & 7 & 0 & 3 & 0 \\
\hline \multirow{4}{*}{ Ceratorhiza } & 1 & 11 & 7 & 7 & 4 & 3 & 0 \\
\hline & 2 & 10 & 10 & 10 & 0 & 3 & 0 \\
\hline & 3 & 10 & 7 & 7 & 3 & 3 & 0 \\
\hline & 4 & 8 & 9 & 3 & 6 & 2 & 1 \\
\hline \multirow[t]{4}{*}{ Trichoderma } & 1 & 8 & 8 & 8 & 0 & 3 & 0 \\
\hline & 2 & 5 & 5 & 5 & 0 & 3 & 0 \\
\hline & 3 & 11 & 10 & 10 & 1 & 3 & 0 \\
\hline & 4 & 7 & 6 & 7 & 0 & 3 & 0 \\
\hline
\end{tabular}


Table 2. Mean effectiveness of orchid mycorrhizal test results at $2^{\text {nd }}$ week

\begin{tabular}{|c|c|c|c|c|c|c|c|}
\hline \multirow{2}{*}{$\begin{array}{l}\text { Orchid } \\
\text { mycorrhizal } \\
\text { isolates }\end{array}$} & \multirow{2}{*}{$\begin{array}{l}\text { Duration of } \\
\text { incubation } \\
\text { (Day) }\end{array}$} & \multicolumn{6}{|c|}{ Observation of effectiveness test ( $2^{\text {nd }}$ week) } \\
\hline & & $\sum_{\text {(Initial) }}$ Root & $\sum_{\text {(End) }}$ Root & $\begin{array}{l}\sum_{\text {(Life) }} \text { Root } \\
\text { Rete }\end{array}$ & $\sum_{\text {(Dead) }}$ Root & $\begin{array}{l}\sum_{\text {(Life) }} \text { Plantlet } \\
\text { (Life }\end{array}$ & $\sum_{\text {(Dead) }}$ Plantlet \\
\hline Control & - & 7 & 7 & 7 & 0 & 3 & 0 \\
\hline \multirow[t]{4}{*}{ Ceratorhiza } & 1 & 7 & 7 & 7 & 0 & 3 & 0 \\
\hline & 2 & 7 & 5 & 5 & 2 & 3 & 0 \\
\hline & 3 & 8 & 9 & 9 & 1 & 3 & 0 \\
\hline & 4 & 3 & 3 & 3 & 3 & 3 & 0 \\
\hline \multirow[t]{4}{*}{ Trichoderma } & 1 & 8 & 7 & 7 & 1 & 3 & 0 \\
\hline & 2 & 5 & 5 & 5 & 0 & 3 & 0 \\
\hline & 3 & 10 & 10 & 9 & 3 & 3 & 0 \\
\hline & 4 & 6 & 5 & 5 & 1 & 3 & 0 \\
\hline
\end{tabular}

Table 3. Mean effectiveness of orchid mycorrhizal test results at $3^{\text {rd }}$ week

\begin{tabular}{|c|c|c|c|c|c|c|c|}
\hline \multirow{2}{*}{$\begin{array}{l}\text { Orchid } \\
\text { mycorrhizal } \\
\text { isolates }\end{array}$} & \multirow{2}{*}{$\begin{array}{l}\text { Duration of } \\
\text { incubation } \\
\text { (Day) }\end{array}$} & \multicolumn{6}{|c|}{ Observation of effectiveness test ( $3^{\text {rd }}$ week) } \\
\hline & & $\sum_{\text {(Initial) }}$ Root & $\begin{array}{l}\sum_{\text {(End) }} \text { Root } \\
\text { (End }\end{array}$ & $\begin{array}{l}\sum_{\text {(Life) }} \text { Root } \\
\text { (Le) }\end{array}$ & $\begin{array}{l}\sum_{\text {(Dead) }} \text { Root } \\
\text { (Dear }\end{array}$ & $\begin{array}{l}\sum_{\text {(Life) }} \text { Plantlet } \\
\text { life }\end{array}$ & $\sum_{\text {(Dead) }}$ Plantlet \\
\hline Control & - & 7 & 7 & 7 & 0 & 3 & 0 \\
\hline \multirow[t]{4}{*}{ Ceratorhiza } & 1 & 7 & 7 & 7 & 0 & 3 & 0 \\
\hline & 2 & 8 & 8 & 8 & 0 & 3 & 0 \\
\hline & 3 & 10 & 7 & 7 & 3 & 3 & 0 \\
\hline & 4 & 3 & 3 & 3 & 0 & 3 & 0 \\
\hline \multirow[t]{4}{*}{ Trichoderma } & 1 & 7 & 7 & 7 & 0 & 3 & 0 \\
\hline & 2 & 5 & 5 & 5 & 0 & 3 & 0 \\
\hline & 3 & 11 & 11 & 11 & 0 & 3 & 0 \\
\hline & 4 & 5 & 5 & 5 & 0 & 3 & 0 \\
\hline
\end{tabular}

Table 4. Mean effectiveness of orchid mycorrhizal test results at $4^{\text {th }}$ week

\begin{tabular}{|c|c|c|c|c|c|c|c|}
\hline \multirow{2}{*}{$\begin{array}{l}\text { Orchid } \\
\text { mycorrhizal } \\
\text { isolates }\end{array}$} & \multirow{2}{*}{$\begin{array}{l}\text { Duration of } \\
\text { incubation } \\
\text { (Day) }\end{array}$} & \multicolumn{6}{|c|}{ Observation of effectiveness test $\left(4^{\text {th }}\right.$ week) } \\
\hline & & $\sum_{\text {(Initial) }}$ Root & $\begin{array}{l}\sum_{\text {(End) }} \text { Root } \\
\text { (End }\end{array}$ & $\begin{array}{l}\sum_{\text {(Life) }} \text { Root } \\
\end{array}$ & $\begin{array}{l}\sum_{\text {(Dead) }} \text { Root } \\
\end{array}$ & $\begin{array}{l}\sum_{\text {(Life) }} \text { Plantlet } \\
\text { ilent }\end{array}$ & $\sum_{\text {(Dead) }}$ Plantlet \\
\hline Control & - & 7 & 7 & 7 & 0 & 3 & 0 \\
\hline \multirow{4}{*}{ Ceratorhiza } & 1 & 7 & 8 & 8 & 0 & 3 & 0 \\
\hline & 2 & 8 & 10 & 7 & 3 & 3 & 0 \\
\hline & 3 & 7 & 9 & 9 & 1 & 3 & 0 \\
\hline & 4 & 3 & 5 & 5 & 0 & 3 & 0 \\
\hline \multirow[t]{4}{*}{ Trichoderma } & 1 & 7 & 5 & 5 & 2 & 3 & 0 \\
\hline & 2 & 5 & 7 & 5 & 2 & 3 & 0 \\
\hline & 3 & 9 & 9 & 9 & 3 & 3 & 0 \\
\hline & 4 & 5 & 6 & 6 & 0 & 3 & 0 \\
\hline
\end{tabular}

The test results showed that the Ceratorhiza inoculation treatment showed a fluctuation in the mean increase in the number of final roots, live roots, dead roots, and dead plantlets that were higher than the Trichoderma inoculation treatment. The highest observation of the highest final root number in Ceratorhiza inoculation was at incubation time of 1 day which was 3 at week 2 (Table 2) and 2 at week 4 (Table 4), whereas at Tricodherma inoculation was at incubation time at 3 day namely 4 at week 3 (Table 3 ) and 2 at week 4 (Table 4). 


\section{Ceratorhiza}

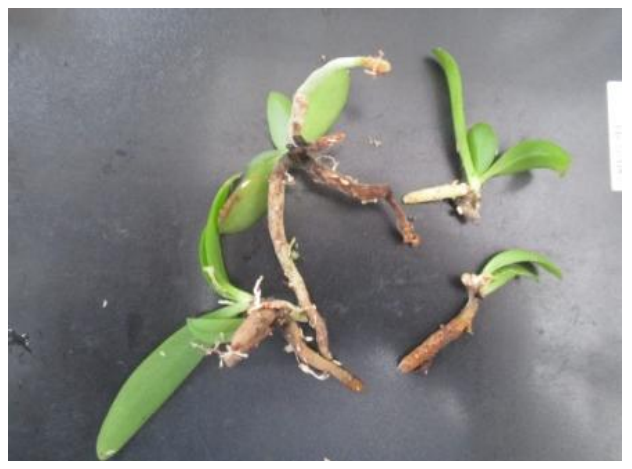

2

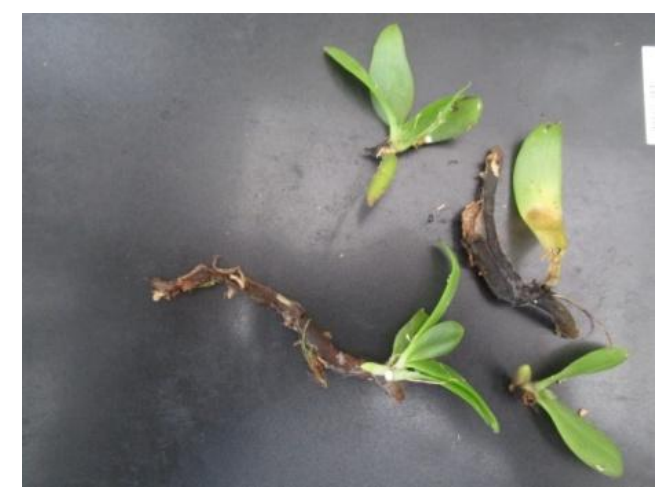

3

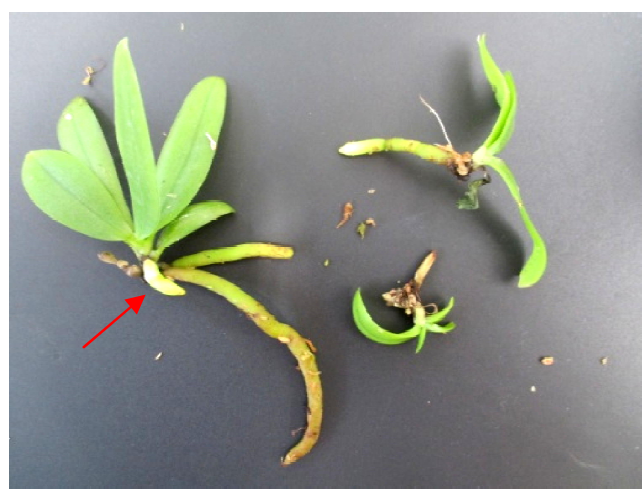

4

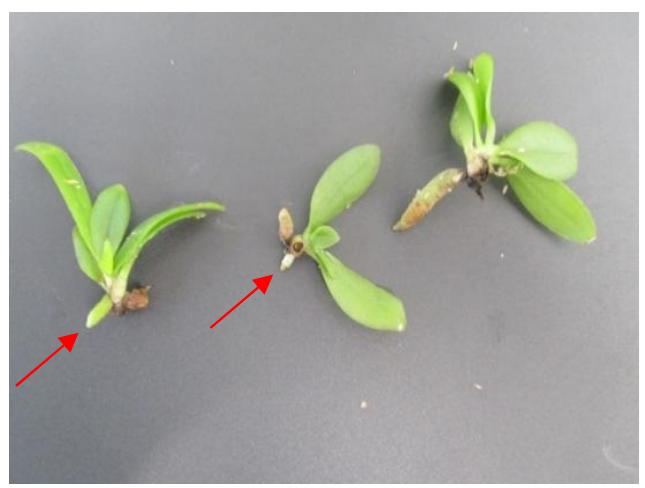

Trichoderma
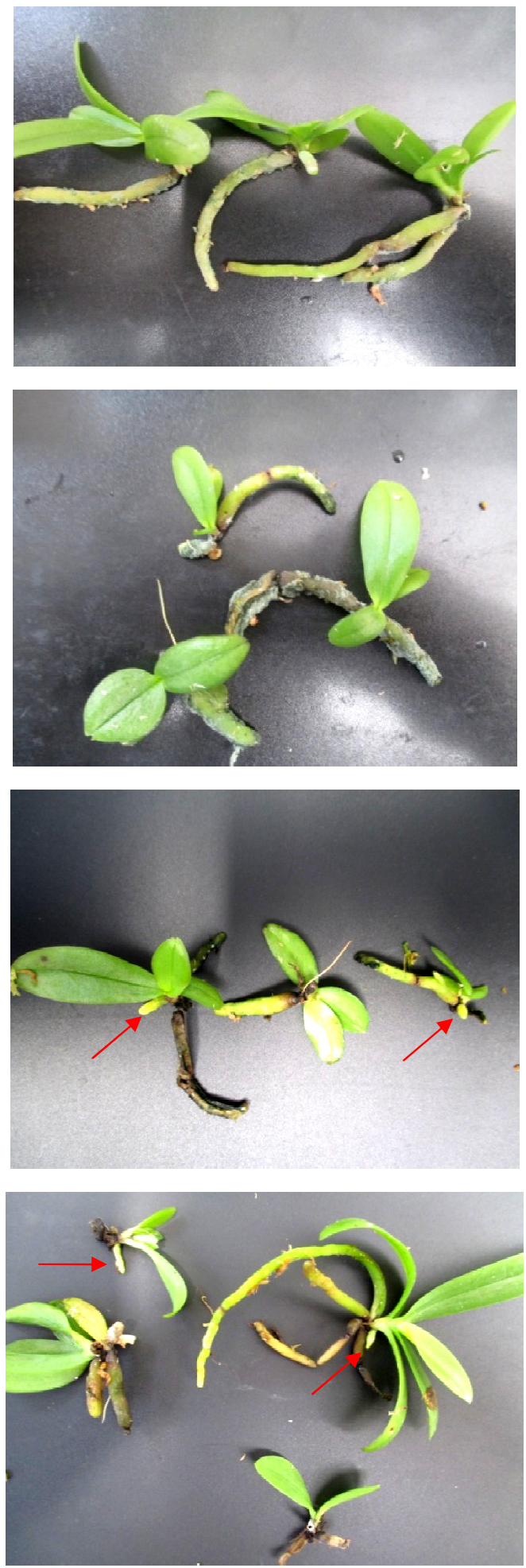

Fig. 2. Development of plantlet results from mycorrhizal inoculation per week; (1) week 1; (2) week 2; (3) week 3; (4) week 4. The arrows indicate the emergence of new roots 
The highest number of life roots in Ceratorhiza inoculation was at 4 days incubation ie 1 at week 3 (Table 3) and -3 at week 4 (Table 4), whereas at Trichoderma inoculation was at 4 day incubation time at 4 at week 3 (Table 3) and 4 weeks (Table 4). The highest mean number of dead roots in Ceratorhiza inoculation was at incubation time of 1 day which was 3 at week 3 (Table 3) and 6 at week 4 (Table 4), whereas at Trichoderma inoculation was at incubation time of 2 days namely 3 at week 3 (Table 3 ) and 1 at week 4 (Table 4). Finally, the mean observation the highest number of dead plantlets in Ceratorhiza inoculation was at an incubation time of 1 day which is 1 at week 4 (Table 4 ), whereas in Trichoderma inoculation no dead plantlets were found.

The results of this study showed that the inoculation of Ceratorhiza gave more effect on the number of dead roots in week 1 and 2 compared to Trichoderma inoculation. Although at weeks 3 and 4 a large number of new roots appear (Fig. 2). The results also showed that the best inoculation time for Ceratorhiza and Trichoderma was day 3 and 4 . This adaptation process stopped at the beginning of week 4 . As of week 4 , the mean number of dead roots decreased and the number of root increases increased. Based on visual observations, the root undergoes decay as a process of adaptation to the orchid my corrhizal inoculation treatment. This is due to the faster growth of Ceratorhiza hypha so that it can associate with plants faster. The faster the orchid mycorrhizal is associated with the host plant, the higher the capacity to absorb nutrients and cause increased growth. Muslim et al. [9] explained that the main principle of orchid mycorrhizal work is to infect the root system of the host plant and produce hyphae intensively so that it can increase the capacity of plants to absorb nutrients.

Orchid plants require orchid mycorrhizal infections to complete their life cycle. An important role of orchid mycorrhizal in plant growth is its ability to absorb nutrients both macro and micro. The treatment of orchid mycorrhizal inoculation on orchids is known to be able to increase the efficiency of inhibition of $\mathrm{N}$ nutrient absorption to increase plant growth, such as increasing length, width, and the number of leaves and roots. Element $\mathrm{N}$ is a building material for amino acids/ proteins, enzymes, nucleic acids, nucleoproteins, and alkaloids. $\mathrm{N}$ deficiency will limit cell division and distribution [10].

\section{CONCLUSION}

The results of the effectiveness of orchid mycorrhizal isolates in Indonesia and its role as biofertilizer showed that the inoculation treatment of Ceratorhiza showed fluctuations in the average increase in the number of final roots, life roots, dead roots, and dead plantlets which were higher than those in the Trichoderma inoculation treatment. The results also showed that the best inoculation time on Ceratorhiza and Trichoderma was day 3 and 4 . The adaptation process had the effect of increasing the number of dead roots in week 1 and 2 . The adaptation process stopped at the beginning of week 4 with the number of new roots appearing a lot.

\section{COMPETING INTERESTS}

Authors have declared that no competing interests exist.

\section{REFERENCES}

1. Shao SC, Burgess KS, Sanders JMC, Liu $\mathrm{Q}$, Fan $\mathrm{XL}$, Huang $\mathrm{H}$, Gao JY. Using in situ symbiotic seed germination to restore over-collected medicinal orchids in Southwest China. Front Plant Sci. 2017;8: 888.

2. Silva JAT, Kerbauy GB, Zeng S, Chen $Z$, Duan J. In vitro flowering of orchids. Reviews in Biotechnology. 2013;34(1).

3. Wu PH, Huang DD, Chang DCN. Mycorrhizal symbiosis enhances Phalaenopsis orchid's growth and resistance to Erwinia chrysanthemi. African Journal of Biotechnology. 2011;10(50):10095-10100.

4. Wu FH, Chan MT, Liao DC, Hsu CT, Lee YW, Daniell $H$, Duvall MR, Lin CS. Complete chloroplast genome of Oncidium gower ramsey and evaluation of molecular markers for identification and breeding in Oncidiinae. BMC Plant Biology. 2010;10(68):1-12.

5. Tong TG. Research Focus: Beneficial Endophytes in plants; 2019.

Available:http://abrc.sinica.edu.tw/2010E/vi ew2/faculty_E1_Print.php?id=cgtong

(Accessed October $11^{\text {th }}$ 2019)

6. Soelistijono Priyatmojo A, Semiarti E, Sumardiyono C. Characterization of pathogenic Rhizoctonia sp. and 
mycorrhizal Rhizoctonia isolates on terrestrial orchid plant Spathoglottis plicata. Biota. 2011;16(2):371-380.

7. Gopireddy BM, Devi GU, Kumar KV, Babu TR, Naidu TCM. Cultural and morphological characterization of Rhizoctonia solani f. sp. sasakii isolates collected from different districts of Andhra Pradesh. Int. J. Curr. Microbiol. App. Sci. 2017;6(11):3457-3469.

8. Nuangmek W, Mckenzie EHC, Lumyong S. Endophytic fungi from wilt banana (Musa accuminata colla) work againts antracnose disease caused by Colletotricum musae. Research Journal of Microbiology. 2008;3(5):368-374.

9. Muslim A, Horinouchi $\mathrm{H}$, Hyakumachi M. Biocontrol of Fusarium wilt of spinach by the plant growth promoting fungus Fusarium equiseti Gf18. Journal of Plant Pathology. 2010;92(1):146-254.

10. Alghamdi SA. Influence of mycorrhizal fungi on seed germination and growth in terrestrial and epiphytic orchids. Saudi Journal of Biological Sciences. 2019;26(3): 495-502.

(c) 2019 Mahfut et al.; This is an Open Access article distributed under the terms of the Creative Commons Attribution License (http://creativecommons.org/licenses/by/4.0), which permits unrestricted use, distribution, and reproduction in any medium, provided the original work is properly cited.

Peer-review history:

The peer review history for this paper can be accessed here: http://www.sdiarticle4.com/review-history/52125 